The Sustainable City XIII 161

\title{
ACTIVITIES TRAINING ON CITY LOGISTICS: CASE STUDY OF THE CALABRIA REGION, ITALY
}

\author{
TOMMASO CALABRÒ, GIUSEPPE IIRITANO \& MARIA ROSARIA TRECOZZI \\ Regione Calabria, Italy
}

\begin{abstract}
The Calabria Region is among a few European regions that have financed a specific program for the implementation of city logistics policies. The Calabria Region is the only government in Italy that has developed an Implementation Plan and related Call to finance design and realization of city logistics in the last 10 years. The Region wants to pursue European sustainability targets to bring the Calabria people to be among the best in Europe by improving the livability of urban centers even with an efficient freight distribution. Starting with a Regional Transport Plan, the Calabria Region has implemented a set of different activities of public engagement carried out by regional offices to involve all stakeholders to make decisions on city logistics procedures. Among these activities are training activities including seminars, workshops, tabletops and games. The paper analyses the training activities on city logistics. Training activities are an element of the general planning process of the Regional Transport Plan, which has been implemented to support all cities involved in city logistics projects and to improve capability of all stakeholders such as public employees and managers, experts and researchers, associations, and authorities. According to literature, a classification training activities is proposed. In particular, the US training approaches are analysed and the training activities on city logistics in the case of the Calabria Region for city logistics is presented.
\end{abstract}

Keywords: city logistics, training, sustainable development, urban transport.

\section{INTRODUCTION}

Freight transport has negative externalities on sustainability development in environmental, economic and social terms [1]. One of the main objectives of city logistics concerns the reduction of these externalities without depressing economic and social vitality of urban areas [2]-[6].

To reduce the impacts of freight transport in urban areas it is necessary to implement city logistics measures. There is a wide range of city logistics measures that can be grouped into different categories [7]-[10]: supply management, demand management, infrastructural actions, ICT and ITS application, environment-friendly vehicle, support for public-private collaboration, reverse logistics.

From some years, the local administrations have revealed a high interest on freight transport at urban level and, in particular, on realization of city logistics measures to reduce negative externalities. Big cities as London, Paris, Barcelona, Rome included freight mobility within their urban transport plans [11]. The small and medium-size cities faced with difficulties in addressing urban logistics due to adversity of retailers and couriers although they are interested to the wellness of citizens and to the general liveability. These difficulties, together with few knowledge and the lack of capability of planning integrated solutions, of managing process evolution and insufficient structure and skills at the level of the single local administration, restrained the development of urban planning.

In Calabria (Italy) there are small and medium-size cities, only in a few cases whit a population exceeding 30,000 inhabitants; high densities of inhabitants and shops characterize these cities; often they are without management of urban distribution of goods and they do not have sufficient structures and skills to develop city logistics planning. 
The regional administration has developed a general planning process that includes city logistics. This process allowed a support of single local administration by several activities of regional offices, including training activities. The support by training activities allowed overcoming difficulties on few knowledge and capability of planning integrated solutions in structures at the level of the single local administration.

It is possible to interpret regional administration action by three interconnected processes that can be identified schematically as in Fig. 1 [12]:

- city planning theories, that are studies to identify the vision and missions perspective for the city;

- city rules, that are regulations and laws, books, guidelines and operative documents;

- $\quad$ city development, that is real city logistics development.

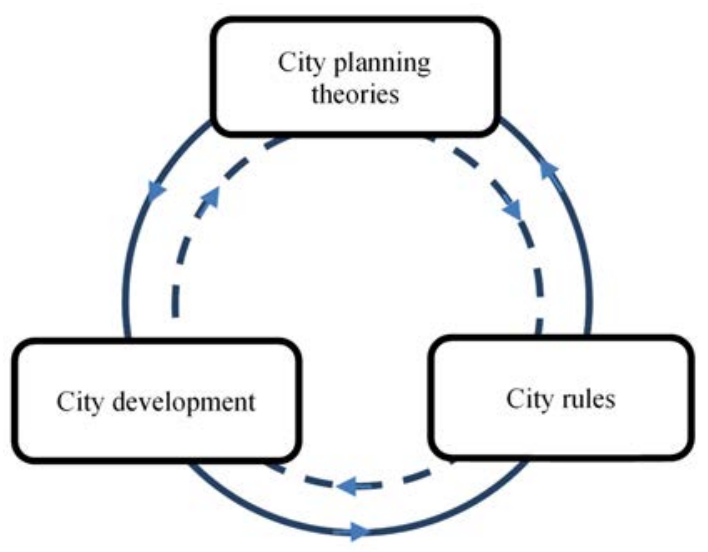

Figure 1: Circular stages among the processes [12].

There are circular stages among city planning theories, rules and development and the smart city is a possible convergence. To achieve this convergence, two circular stages are possible: in the first way, the city planning theory is transposed by decision-makers into city rules to address city development; in the second way, city development influences city rules from which city planning theory.

In this paper, the first way is investigated. Decision-maker is regional administration that pushes city planning theory into city rules to address city development.

In regional administration planning process the bridge from planning theory to city rules is crucial to support local administration to implement Sustainable Urban Mobility Plans (SUMPs), including city logistics.

A SUMP suggest as a new planning concept to solve problems of urban areas in a more sustainable and integrative way. A SUMP is a strategic plan designed to satisfy the mobility needs of people and businesses in cities and their surroundings for a better quality of life. It builds on existing planning practices and takes due consideration of integration, participation, and evaluation principles [13].

A SUMP aims to create an urban transport system to: Ensure all citizens are offered transport options that enable access to key destinations and services; Improve safety and 
security; Reduce air and noise pollution, greenhouse gas emissions and energy consumption; Improve the efficiency and cost-effectiveness of the transportation of persons and goods; Contribute to enhancing the attractiveness and quality of the urban environment and urban design for the benefits of citizens, the economy and society as a whole [14].

\section{ACTIVITIES TRAINING: AN OVERVIEW}

They are activities to increase stakeholders' knowledge in terms of research, learning and training. These activities contribute to improve capability of subjects involved in process planning.

The guidelines of SUMPs are the outcome of the work carried out for the European Commission with the help of training activities, also.

The guidelines are based on a review of existing documents and expert inputs, including numerous contributions from policy makers, planners and other practitioners, academia and other stakeholders received during awareness-raising presentations and training workshops arranged across Europe between 2010 and 2013.

There is not a specific training activities program to increase stakeholders' knowledge on urban planning and, in particular, on city logistics. Therefore, it is necessary to refer to other areas of planning and related training.

USA Department of Homeland Security (DHS) defines capability how a characteristic derived from a combination of properly planned, organized, equipped, trained, and exercised personnel who achieve the intended outcome.

The National Strategy for Homeland Security (NSHS) providing the national initiatives focuses on development of exercise around capabilities-based planning.

Within these the Homeland Security Exercise and Evaluation Program (HSEEP) provides a set of guiding principles for exercise programs, as well as a common approach to exercise program management, design and development, conduct, evaluation, and improvement planning.

HSEEP doctrine is applicable for exercises across all mission areas and it is for use by stakeholders across the whole community.

HSEEP doctrine is based on national best practices and is supported by training, technology systems, tools, and technical assistance [15].

HSEEP defines seven types of exercises classified in Fig. 2:

- discussions-based exercises includes seminars, workshops, tabletops and games; these types of exercises can be used to familiarize players with, or develop new, plans, policies, agreements and procedures; these exercises focus on strategic, policy-oriented issues; facilitators and/or presenters usually lead the discussion, keeping participants on track towards meeting exercise objectives; they are normally used as starting points in the building-block approach to the cycle, mix, and range of exercises;

- operations-based exercises includes drills, functional exercises and full-scale exercise; these types of exercises can be used to validate plans, policies, agreements and procedures, clarify roles and responsibilities, and identify resource gaps in an operational environment; these exercises focus on tactical response-related issues.

\subsection{Discussion-based exercises}

Discussion-based exercises includes four training activities: seminar, workshop, tabletop and game. 


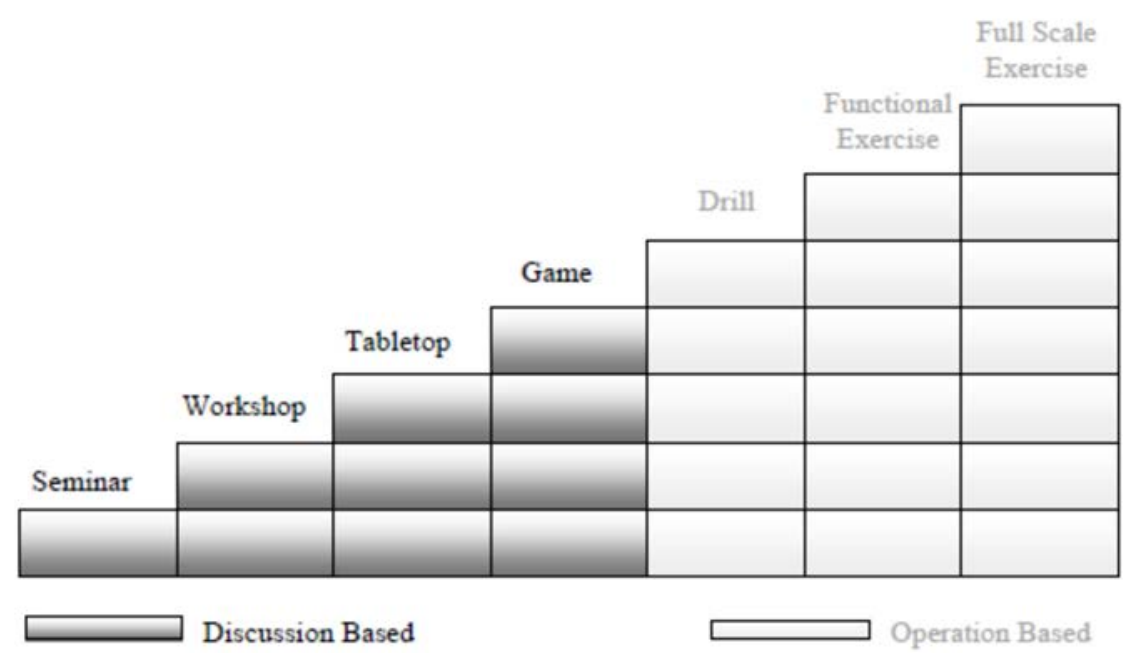

Figure 2: Training activities classification [15].

A seminar is an informal discussion, designed to orient participants to new or updated plans, policies, or procedures; it can be valuable for entities that are developing or making major changes to existing plans or procedures.

A workshop is different to seminar in two aspects: participant interaction is increased, and the focus is placed on achieving or building a product, such as a draft plan or policy; effective workshops entail the broadest attendance by relevant stakeholders.

A tabletop involves key personnel discussing simulated scenarios in an informal setting. It can be used to enhance general awareness, validate plans and procedures, rehearse concepts; during a tabletop, players are encouraged to discuss issues in depth, collaboratively examining areas of concern and solving problems.

A game is a simulation of operations using rules, data, and procedures designed to depict an actual or hypothetical situation; it is useful tool for validating plans and procedures or evaluating resource requirements.

\subsection{Operations-based exercises}

Operations-based exercises includes three training activities: drill, functional exercise, fullscale exercise.

A drill is a coordinated, supervised activity usually employed to validate a specific function or capability in a single agency or organization. Drill is used to provide training on new equipment, validate procedures, or practice and maintain current skills. Drills can also be used to determine if plans can be executed as designed, to assess whether more training is required, or to reinforce best practices.

A functional exercise is designed to validate and evaluate capabilities, multiple functions and/or sub-functions, or interdependent groups of functions. Functional exercise is typically focused on exercising plans, policies, procedures, and staff members involved in management, direction, command, and control functions. In functional exercise events is projected through an exercise scenario with event updates that drive activity typically at the management level. 
A full-scale exercise is typically the most complex and resource-intensive type of exercise. It involve multiple agencies, organizations, and jurisdictions and validate many facets of preparedness. In full-scale exercise events is projected through an exercise scenario with event updates that drive activity at the operational level. The full-scale exercise simulates reality by presenting complex and realistic problems that require critical thinking, rapid problem solving, and effective responses by trained personnel.

\section{ACTIVITES TRAINING: THE CITY LOGISTICS EXAMPLE}

In Calabria, the Regional Transportation Plan (RTP) supports the choices of Calabria Region in terms of transport and logistics, in the medium and long term.

The RTP has been approved in 2016 [16] evaluated positively for environmental aspects by regional government department and evaluated positively also by the EU Commission, Directorate General for Regional and Urban Policy as communicated with note no. 1086324 of $01 / 03 / 2017$.

The general vision of RTP is specified on regional economic development, external and internal accessibility and sustainability.

The RTP defines ten strategic objectives to pursue general vision; each objective corresponds to a strategic action, in turn declined in ten operational measures.

In the Objective 1 Training, Research, Information and Innovation Action 1 Measures to increase training, research, development and technological innovation there is a specific measure related to training activities: Measure 1.3 Everlasting training and strengthen of institutional capability.

The Region supports training programs to achieve high level of capability of employees in regional and local administrations respect to RTP issues.

In the Objective 10 Planning-monitoring coordination and participation Action 10 Measures of planning, monitoring, participation and resources of transport and logistic regional there is a specific measure related to public engagement: Measure 10.6 Participation: Public engagement, Public involvement, Public preliminary investigation.

The Region supports implementation of participatory process by stakeholders such as debate public, public engagement and involvement.

In the Objective 2 Urban areas, Action 2 Measures for infrastructure upgrading and services in urban areas there is a specific measure related to city logistics: Measure 2.5 City Logistics.

The Region supports all interventions that are inspired and related to the actions identified in the Action Plan on Urban Mobility proposing twenty measures to encourage and help local, regional and national authorities in achieving their goals for sustainable urban mobility. With the Action Plan, the European Commission presented for the first time a comprehensive support package in the field of urban mobility [17].

In particular Region supports all interventions that are inspired and related to action $19-$ Urban Freight Transport, both promoting the dissemination of information both with adequate incentive support for participation in all European tenders, and with specific supplementary contributions for municipalities that win national or supplementary European tenders, considering the priorities obtainable with the interventions envisaged by the ROP for efficiency improvement energy

The main aim is Achieve essentially $\mathrm{CO}_{2}$-free city logistics in major urban centres by 2030 as indicated by Transport White Paper [18].

The Region supports all interventions according to SUMPs, which can be implemented by local administrations. The Region bottom up approach follows a transparent and participatory approach of SUMP. The guidelines Developing and Implementing a 
Sustainable Urban Mobility Plan [14] underlines on the role of transparent and participatory approach, which brings citizens and other stakeholders on board from the outset and throughout the plan development and implementation process. Participatory planning is a prerequisite for citizens and stakeholders to take ownership of the Sustainable Urban Mobility Plan and the policies it promotes. It makes public acceptance and support more likely and thus minimises risks for decision-makers and facilitates the plan implementation.

After RTP approved, the general process of City Logistics involved in two more phases:

- programming, concluded in 2017 when regional government approved Implementation Program for the city logistics; the Implementation Program indicates the programmable measures that can be implemented in line with the RTP and EU planning documents and the procedures;

- execution, concluded in 2018 when regional department opened a Call to finance design and realization of city logistics in all the cities of Calabria

o with a population exceeding 30.000 inhabitants;

0 with a population of less than 30.000 inhabitants, in which a Limited Traffic Zone (ZTL) is operational.

In programming and execution phases, city logistics process included a set of different activities carried out by regional offices. Among these activities, there are training activities [19]-[21], which are an example of public engagement.

Calabria Region guided a process to developed different training activities by discussionsbased exercises. These exercises provides the necessary information and documentation to assist all subjects involved in conducting of city logistics. Moreover, the aim is to improve capability of subjects involved, such as authorities, public employees and managers, transport planning experts and researchers, associations.

In Fig. 3 discussion based exercise on city logistics developed are reported.

\subsection{Discussions-based exercises in programming process}

Programming process is finalized to build Implementation Program that indicates the programmable measures that can be implemented and the procedures.

Calabria Region has developed:

- seminar;

- workshops.

PROGRAMMING

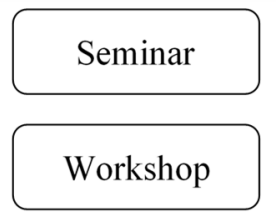

EXECUTION

Seminar

Tabletop

Game

Figure 3: Discussion based exercise on city logistics. 
The seminar (January 2017) was a discussion designed to orient participants to general project of RTP and its measures, in particular city logistics measure, and to related planning procedures; it was useful to discuss on developing to RTP.

The personnel discussing are:

- regional authorities involved on transport planning;

- regional managers working on transport planning;

- experts on transport planning of Transport project.

The Transport project is an activity planned by the Region that commits human and financial resources to support the offices in the implementation of the RTP.

The workshops were developed because Calabria Region wanted to build Implementation Program with a participatory approach. Participatory approach was aimed at engaging stakeholder actively. For this reason participant interaction and broadest attendance by relevant stakeholders have been requested.

In both workshops participants interacted on all aspects of freight distribution sustainability, but the discussion was different due to different skills of the participants.

In the first workshop (June 2017) the focus has been on effects of urban distribution of goods respect to environnement (congestion, air pollution, noise issues [22]-[24]);

The personnel discussing are:

- regional authorities involved on transport planning and environment;

- regional managers working on transport planning and programming of financial funds;

- regional employees working on city logistics;

- experts on transport planning of Transport project;

- principal associations working on environment at regional and national level, such as Italia Nostra, FAI, Touring Club, Legambiente.

In the second workshop (July 2017) the focus has been on effects of freight urban distribution respect to the economy (changes in logistic costs and thus the price of products [25], [26] and the society (an increasing risk of accidents due to a combination of different types of vehicles on the road [27], [28]).

The personnel discussing are:

- regional authorities involved on transport planning, territorial planning, environment, economic development;

- regional managers working on transport planning, environment, programming of financial funds;

- regional employees working on city logistics;

- experts on transport planning of Transport project;

- city managers working on transport planning in cities with a population exceeding 30.000 inhabitants.

In Calabria, there are few cities with a population exceeding 30.000 inhabitants. These cities are obliged to have urban traffic plans based on Italian laws to reduce the negative effects of urban freight transport and to improve the efficiency of the urban supply chain.

Urban traffic plans should be consistent with SUMPs, which are a strategic plans designed to satisfy the mobility needs of people and businesses in cities and their surroundings for a 
better quality of life. A SUMPs is built on planning practices and takes due consideration of integration, participation, and evaluation principles.

\subsection{Discussions-based exercises in execution process}

Execution process is finalized to build a Call to finance design and realization of city logistics in Calabrian cities.

Calabria Region has developed:

- seminar;

- tabletops;

- game.

The seminar (September 2018) was a discussion designed to orient participants on procedures of Call; the seminar happened after the publication of the Call and it was useful to discuss on developing of the procedure to submit the projects.

The personnel discussing are:

- regional authorities involved on transport planning;

- regional managers working on transport planning;

- regional employees working on city logistics;

- experts on transport planning of Transport project;

- city managers working on transport planning in cities with a population exceeding 30,000 inhabitants and other cities with a population of less than 30,000 inhabitants in which a Limited Traffic Zone (ZTL) is operational; these cities are those that can potentially submit a city logistics projects.

The tabletops were developed because Calabria Region wanted to involve key personnel discussing simulated scenarios respect to city logistics problems. It was useful for enhance general awareness and to discuss issues in depth, collaboratively examining based on the latest scientific research also.

In the first tabletop (June 2018) the focus has been on the strategic results, such as reduction of atmospheric and acoustic pollution, reduction of accidents, improvement of accessibility and efficiency of the freight distribution flows with advantages both for citizens and couriers. The tabletop happened before the publication of the Call and it was useful to discuss on developing of the possible measures to realize in the cities considering benefits and costs of city logistics projects.

The personnel discussing are:

- regional authorities involved on transport planning;

- regional managers working on transport planning;

- regional employees working on city logistics;

- experts on transport planning of Transport project;

- researchers from various Italian universities working on city logistics and sustainable mobility;

- city managers working on transport planning in cities with a population exceeding 30.000 inhabitants and other cities with a population of less than 30.000 inhabitants, in which a Limited Traffic Zone (ZTL) is operational;

- representatives of retailers and couriers; 
- principal associations working on environment and on sustainable mobility.

In the second tabletop (June 2019) the focus has been on the strategic results respect to the latest scientific research at national and international level [29]. The tabletop happened after the publication of the funded projects list by Call and it was useful to discuss on developing of the measures will be realized in the cities considering benefits and costs of city logistics projects.

The personnel discussing are:

- regional authorities involved on transport planning;

- regional managers working on transport planning;

- regional employees working on city logistics;

- experts on transport planning of Transport project;

- researchers from various national and international universities working on city logistics and sustainable mobility;

- city managers of 3 cities who submitted the projects and were funded.

Moreover, several tabletops were developed when the Call was open. Experts of Transport project provided technical support, one day a week, at cities to submit at Call.

The game was developed before the publication of the Call ad after execution decision (DGR 391/2017). By the game Calabria Region wanted to simulate actual situation of Calabrian cities; they were a useful tool to validate Implementation Program and to evaluate the requirements underlying the Call on city logistics projects.

The game simulated a test case for a city with population exceeding 30,000 inhabitants [29]. The game happened before the publication of the Call and it was useful to simulate a possible scenario of implementation measures and its results.

Measures and results are among those defined by the Implementation Program.

The measures are:

- $\quad$ supply management;

- infrastructural interventions;

- ICT and ITS application;

- environment-friendly vehicle;

- reverse logistics.

The results are:

- reduction of pollution;

- increase in distribution efficiency;

- $\quad$ sustainability of the project.

\section{CONCLUSION}

Calabria Region is the only government in Italy that has recently developed Implementation Program and related Call to finance cities in design and realization of city logistics in the last ten years. The Region wants to pursue European sustainability targets to bring Calabria people among the best regions people of Europe by improving the livability of urban centers even with an efficient freight distribution.

Starting from RTP, in particular for Measure 2.5 City Logistics, Calabria Region has implemented a set of different training activities carried out by regional offices in programming and execution process. 
Training activities are an example of public engagement in the general framework of the participatory approach that accompanied PRT planning process from 2016 and in progress.

These activities are provided the necessary information and documentation to assist all cities involved in city logistics projects. Moreover, these activities are improved capability on city logistics item of subjects such as authorities, public employees and managers, transport planning experts and researchers, associations.

The training activities made it possible to achieve the important result of supporting local administrations and allowing those who had minimal knowledge in city logistics to carry out quality projects. This made it possible to reach the same level of quality of projects on the regional territory.

Training activities contributed to complete the implementation of Measure 2.5 City Logistics effectively. On this result, the Region is working to develop another call to finance the realization of other city projects.

\section{REFERENCES}

[1] Cascetta, E., Transportation Systems Engineering: Theory and Methods, Springer Science and Business Media, 2013.

[2] Russo, F., Modelling behavioral aspects of urban freight movement. Freight Transport Modelling, eds M. Ben-Akiva, H. Meersman \& E. Van de Voorde, Emerald Group, Bingley, 2013.

[3] Comi, A., Donnelly, R. \& Russo, F., Urban freight models. Modelling Freight Transport, eds L. Tavasszy \& J. De Jong, Elsevier, pp. 163-200, 2014.

DOI: 10.1016/B978-0-12-410400-6.00008-2.

[4] Browne, M., Allen, J. \& Alexander, P., Business improvement districts in urban freight sustainability initiatives: A case study approach. Transportation Research Procedia, 12, pp. 450-460, 2015.

[5] Taniguchi, E., City logistics for sustainable and liveable cities. Green Logistics and Transportation: A Sustainable Supply Chain Perspective, eds B. Fahimia, M.G.H. Bell, D.A. Hensher \& J. Sarkis, Springer: Cham, Switzerland, pp. 49-60, 2015.

[6] Taniguchi, E. \& Thompson, R. (eds), City Logistics 3: Towards Sustainable and Liveable Cities, Wiley, 2018.

[7] BESTUFS, BESTUFS: Good Practice Guide on Urban Freight, 2007. www.bestufs.net.

[8] Russo, F. \& Comi, A., A modelling system to simulate goods movements at an urban scale. Transportation, 37(6), pp. 987-1009, 2010. DOI: 10.1007/s11116-010-9276-y.

[9] Musolino, G., Rindone, C., Polimeni, A. \& Vitetta, A., Planning urban distribution center location with variable restocking demand scenarios: General methodology and testing in a medium-size town. Transport Policy, 80, pp. 157-166, 2019.

[10] Musolino, G., Rindone, C. \& Vitetta, A., Passengers and freight mobility with electric vehicles: A methodology to plan green transport and logistic services near port areas. Transportation Research Procedia, 37, pp. 8-393, 2019.

[11] Nuzzolo, A., Comi, A., Ibeas, A. \& Moura, J.L., Urban freight transport and city logistics policies: Indications from Rome, Barcelona and Santander. International Journal of Sustainable Transportation, 10(6), pp. 552-566, 2016. DOI: $10.1080 / 15568318.2015 .1014778$.

[12] Russo, F., Panuccio, P. \& Rindone, C., European plans for smart city: From theories and rules to logistics test case. European Planning Studies, 2016.

DOI: $10.1080 / 09654313.2016 .1182120$. 
[13] European Commission, Sustainable Urban Mobility Plans, 2013.

https://ec.europa.eu/transport/themes/urban/urban_mobility/urban_mobility_actions/s ump_en.

[14] European Commission, Guidelines Developing and Implementing a Sustainable Urban Mobility Plan, 2013.

[15] Department of Homeland Security, Homeland Security Exercise and Evaluation Program (HSEEP), 2007. https://hseep.dhs.gov/pages/1001_HSEEP7.aspx. Accessed on: Jun. 2019.

[16] Calabria Region, Regional Transport Plan, 2016. www.regione.calabria.it/website/ organizzazione/dipartimento6/subsite/pianoregionale. Accessed on: Jul. 2019.

[17] European Commission, Action Plan on Urban Mobility, 2009. https://ec.europa.eu/transport/themes/urban/urban_mobility/action_plan_en.

[18] European Commission, Roadmap to a single European transport area: Towards a competitive and resource efficient transport system, White Paper, 2011.

https://ec.europa.eu/transport/themes/strategies/2011_white_paper_en.

www.eltis.org/sites/default/files/sump_guidelines_en.pdf

[19] Russo, F., Rindone, C. \& Trecozzi, M.R., The role of training in evacuation. WIT Transactions on Information and Communication Technologies, vol. 44, WIT Press: Southampton and Boston, pp. 491-502, 2012.

[20] Russo, F. \& Rindone, C., Civil risk manager at European level. WIT Transactions on Ecology and the Environment, vol. 173, WIT Press: Southampton and Boston, pp. 765-778, 2013.

[21] Russo, F. \& Rindone, C., Urban exposure: Training activities and risk reduction. The Sustainable City IX, 2, p. 991, 2014.

[22] Waygood, E.O.D., Chatterton, T. \& Avineri, E., Comparing and presenting city-level transportation $\mathrm{CO}^{2}$ emissions using GIS. Transportation Research Part D, 24, pp. 127-134, 2013.

[23] Taniguchi, E., City logistics for sustainable and liveable cities. Green Logistics and Transportation: A Sustainable Supply Chain Perspective, eds B. Fahimia, M.G.H. Bell, D.A. Hensher \& J. Sarkis, Springer: Cham, Switzerland, pp. 49-60, 2015.

[24] Russo, F. \& Comi, A., Urban freight transport planning towards green goals: Synthetic environmental evidence from tested results. Sustainability, 8(4), p. 381, 2016. DOI: $10.3390 / \mathrm{su} 8040381$.

[25] Russo, F. \& Musolino, G., A unifying modelling framework to simulate the spatial economic transport interaction process at urban and national scales. Journal of Transport Geography, 24, pp. 189-197, 2012.

[26] Taniguchi, E., Fwa, T.F. \& Thompson, R.G., Urban Transportation and Logistics: Health, Safety, and Security Concerns, CRC Press: Baca Raton, 2013.

[27] Elvik, R., Vaa, T., Erke, A. \& Sorensen, M., The Handbook of Road Safety Measures, Emerald Group: Bingley, 2009.

[28] Russo, F. \& Comi, A., From the analysis of European accident data to safety assessment for planning: The role of good vehicles in urban area. European Transport Research Review, 9(9), pp. 1-12. 2017. DOI 10.1007/s12544-017-0225-0.

[29] Russo, F. \& Comi, A., From city logistics theories to city logistics planning. City Logistics 3: Towards Sustainability and Liveable Cities, eds E. Taniguchi \& R.G. Thompson, Wiley, London, pp. 329-348, 2018. 